\title{
Las indicaciones geográficas y las denominaciones de origen de productos agroalimentarios en la República Argentina a veinte años de la sanción de la Ley $\mathbf{N}^{\circ} 25.380$
}

\section{Geographical indications regarding food and agriculture products in the Argentine Republic twenty years after the enactment of Law 25.380}

\section{Marcela S. Molina}

\author{
Doctora en Ciencias Jurídicas \\ Universidad de Mendoza, Argentina \\ Correo electrónico: marcsmolina@yahoo.com.ar \\ http://orcid.org/0000-0003-3902-4619
}

\section{Resumen}

En el presente artículo, la autora analiza el sistema de indicaciones de origen geográfico de los productos agrícolas (excepto los vinos), en tanto régimen sui generis esencialmente de derecho público. Este marco normativo fue sancionado por el legislador como estrategia de política

\section{Cómo citar este artículo:}

Molina, M. S. (2020). Las indicaciones de origen geográfico en los productos agroalimentarios en la República Argentina a veinte años de la sanción de la Ley 25.380. Revista de la Facultad de Derecho y Ciencias Políticas, 50 (133), pp. 374-402.

doi: http://dx.doi.org/10.18566/rfdcp.v50n133.a07

Recibido: 03 de mayo de 2019.

Aprobado: 02 de diciembre de 2019. 
agrícola, encaminada al fomento de las economías regionales y como parte de un programa de valorización de productos agrícolas. En particular, se analiza la complejidad y la dispersión del régimen jurídico derivado de la distribución constitucional de competencia Nación-provincia, su finalidad, sus características y se estudia si dicho marco jurídico era adecuado para alcanzar los objetivos iniciales.

\section{Palabras clave}

Denominación de origen, indicaciones geográficas, indicaciones de procedencia, fomento, sellos de calidad.

\section{Abstract}

In this paper, the author analyses the geographical origin system of indications of agricultural products (except wines), as a sui generis regime essentially belonging to public law. This regulatory framework was enacted by the parliament as an agricultural policy strategy, intended to promote regional economies and as a part of a plan to enhance the value of agricultural products. In particular, it analyses the complexity and dispersion of the legal regime derived from the constitutional distribution of the Nation-Province jurisdiction, its aim, its characteristics, and whether this legal framework was adequate to achieve its initial objectives

\section{Key words}

Appellations of origin, geographical indications, indications of source, promotion, quality seal.

\section{Introducción}

Las distintas categorías de indicaciones de origen geográfico ${ }^{1}$ han sido incorporadas sucesivamente en el Convenio de París de 1883 (revisión de Washington de 1911) y en el Acuerdo de los Aspectos de los Derechos de Propiedad Intelectual afectados al Comercio (ADPIC) firmado en Marrakech en el seno de la Organización Mundial del Comercio (OMC). También, ha sido prevista en pactos sectoriales relativos a un producto específico, como el Convenio internacional del aceite de oliva y las aceitunas de mesa (2005), firmado en Ginebra (Suiza) el 28 de abril de 2005 en el seno de la United Nations Conference on Trade and Development (UNCTAD).

\footnotetext{
$\overline{1 \text { Los distintos países }}$ regularon la Indicación de Procedencia (IP), Indicación Geográfica (IG) y Denominación de Origen (DO) con distinto sentido y alcance. Por ello, el Comité Permanente sobre Marcas, Dibujos y Modelos Industriales e Indicaciones Geográficas propuso el uso de la expresión indicaciones de origen geográfico como término genérico que comprende las tres categorías: IG, IP y DO, (SCT 8/5, 2002, parágrafo 5 a 8).
} 
Mediante la Ley 24.425 (1994), la República Argentina aprobó el Acuerdo sobre los ADPIC. Seis años más tarde, la Ley 25.380 (2000) —modificada por la Ley 25.966 (2004)- instituyó el régimen de indicaciones de origen geográfico para los productos agroalimentarios, excepto los vinos que se rigen por la Ley 25.163 (1999). Varios años después el Poder Ejecutivo Nacional (PEN) dictó el Decreto 556 (2009) que reglamentó aquella ley. El Congreso Nacional también aprobó el Convenio internacional del aceite de oliva y las aceitunas de mesa de 2005 (Ginebra) por Ley 26.433 (2008).

El Gobierno nacional emitió reglamentos y actos administrativos dentro del ámbito de la SAGyP tendientes a promover la organización e integración de los agricultores y productores, su capacitación, la valorización de los productos a partir de su tipicidad, el fomento del uso de indicaciones geográficas, articulando medios económicos y jurídicos. Los gobiernos provinciales también sancionaron regímenes locales de DO e IG.

Las indicaciones geográficas pueden ser estudiadas desde distintos puntos de vista en el ordenamiento jurídico argentino: en cuanto a su naturaleza jurídica y signo distintivo, como sello de calidad específica, como estrategia de fomento, como patrimonio cultural inmaterial, y en cuanto a las vías legales de defensa, etc.

En el presente trabajo analizamos el sistema de indicaciones de origen geográfico de los productos agrícolas (excepto los vinos sujetos a un régimen especial) durante los últimos diez años, esto es, desde el año 2009 (fecha en que se dictó la reglamentación de la Ley 25.380) hasta nuestros días. Estudiaremos su complejidad y dispersión (normas nacionales y provinciales), a partir del deslinde de competencia Nación-provincias y la necesaria coordinación de los distintos niveles de gobierno competentes en esta materia; asimismo, su finalidad, características, indagando si el marco jurídico vigente ha sido adecuado para cumplir con los objetivos y finalidades que motivaron su sanción.

Tomaremos como indicadores los programas de calidad de productos agroalimentarios y agregado de valor; como variables: los medios económicos y jurídicos utilizados por las autoridades gubernamentales nacionales y locales.

Desde el punto de vista metodológico, esta investigación es exploratoria, deductiva y se apoya en la revisión y exégesis de fuentes formales (tratados internacionales, leyes, reglamentos, actos administrativos nacionales y provinciales) y materiales. 
La primera parte de este artículo es descriptiva, se parte de los antecedentes normativos nacionales y provinciales, las normas del Mercosur y de los primeros actos administrativos, que reconocieron y ordenaron el registro de las indicaciones de origen geográfico de productos agrícolas. Luego entramos en el sistema jurídico vigente, instituido por la Ley 25.380 (2000) y las demás normas complementarias. En la tercera parte efectuamos un análisis crítico de los defectos y omisiones, mediante una visión retrospectiva de la experiencia argentina en el uso de las indicaciones de origen geográfico. Finalmente, en la conclusión plantearemos los desafíos para su consolidación.

\section{Primera parte}

\section{El marco normativo sobre las indicaciones de origen geográfico anterior a la sanción de la Ley 25.380}

La Ley 17.011 (1966) aprobó el Convenio de París de 1883 sobre propiedad industrial, al incorporarlo en el derecho interno argentino. Pocos años después, se sancionó el Código Alimentario Argentino (CAA) (1969) actualmente vigente. Ésta, fue la primera norma argentina que previó disposiciones sobre las indicaciones de procedencia y denominaciones de origen.

El art.236 del CAA (1969) se refiere a las DO, diciendo: "las denominaciones geográficas de un país, región o población no podrán usarse en la designación de los productos elaborados en otros lugares cuando puedan inducir a engaño”. Exceptúa a aquellas DO extranjeras que, por el uso, se transformaron en genéricas para determinados alimentos.

La omisión o la expresión errónea configura una infracción, pasible de sanciones administrativas enunciadas en los arts.9 a 11 de la Ley 18.284 (1969). Estas infracciones son formales, esto es, es suficiente la acreditación de la conducta antijurídica independientemente que haya o no habido confusión o engaño del consumidor.

Estas disposiciones establecieron una regla general del uso de la DO e IP; pero no reglamentaron su reconocimiento, registro y defensa. Tampoco prohibieron registrar indicaciones de origen geográfico como marcas ni establecieron reglas para resolver los conflictos con otros signos distintivos. 
En el año 1980 (catorce años después de la ratificación del Convenio de París de 1883 por la República Argentina) se sancionó la Ley 22.362 (1980). Esta norma legal se limitó a prohibir la registración como marca a las DO nacionales o extranjeras, pero no reglamentó su reconocimiento, protección, registro y uso.

No obstante, los titulares de algunas DO extranjeras se opusieron al registro de una marca conformada por ese nombre geográfico, acreditando su reconocimiento y registro en el país de origen. La jurisprudencia admitió estas oposiciones in re "Institut National des Appellations D’Origine con Resia" y “Valentín Bianchi SACI con Instituto National des Appellations D’Origine”, invocando la citada norma legal (Molina, 2017).

Es importante resaltar, que la prohibición existente en el régimen marcario era insuficiente para la efectiva protección de las indicaciones de origen geográfico, toda vez que no contemplaba las otras categorías (IG, IP).

Tres años después, la Ley 22.802 (1983) de Lealtad Comercial, receptó un concepto de DO similar al desarrollado en la Ley de Marcas. La autoridad de aplicación es la Secretaría de Comercio en el ámbito nacional; los gobiernos provinciales son competentes en el ámbito local.

Más allá de la prohibición de identificar mercaderías con DO nacionales o extranjeras, esta Ley 22.802 (1983) planteaba muchos interrogantes: algunos referidos a la existencia o no de atribución de la Secretaría de Comercio para determinar los efectos de una DO extranjera no registrada en la Argentina (por inexistencia de registro hasta el año 2009), las facultades para verificar su existencia, registro y vigencia de la DO en su país de origen o para determinar si había pasado al uso común.

\section{Normas emanadas de los órganos del Mercosur}

La Decisión 8 (1995) del Consejo del Mercado Común (CMC)-Mercosur: "Protocolo de armonización de normas sobre Propiedad Intelectual en el Mercosur”, contempló y definió sólo la IP y la DO, aplicándolo a productos agrícolas, artesanías y servicios.

Por su parte, la Resolución 26 (2003) del Grupo Mercado Común (GMC), sobre etiquetado, prohibió el uso de DO en la rotulación o en la propaganda de alimentos cuando esto pueda inducir a equívoco o engaño al consumidor. 
En nuestro país, estas normas dictadas por los órganos del Mercosur, en virtud de las atribuciones del Tratado de Asunción, tienen una jerarquía superior a las leyes (Tratado de Ouro Preto, 1994, art. 40). Según el art.15 del Tratado de Ouro Preto (1994), las normas dictadas por este órgano, es obligatoria para los Estados partes, debiendo incorporarse a los ordenamientos jurídicos nacionales, mediante el procedimiento que determine la legislación de cada país.

En este sentido, Boggiano (1995, p.281) dice: "Las normas dictadas en su consecuencia son tanto las normas constitucionales de los órganos supraestatales como las normas derivadas de aquellas, dictadas en su consecuencia”.

La legislación interna argentina no se ajusta a las normas del Mercosur. El texto originario de la Ley 25.380 (2000) preveía la IP y DO. En efecto, esta norma fue modificada por la Ley 25.966 suprimiendo la IP e incorporando la IG (Molina, 2015).

\section{Las Resoluciones de la SAG y P}

Nuestro país no tenía la tradición de identificar los productos agrícolas por su origen geográfico y el consumidor desconocía el sistema de identificación de origen.

Sin embargo, la doctrina había destacado su utilidad para el crecimiento económico (Schiavone, 2006; Sampedro, 2011; Esquivel, 2014), el desarrollo rural sustentable (Pastorino, 2005; Vandecandelaere, 2011; Carrau, 2008) y la protección del patrimonio cultural (Molina, 2018). Pastorino (2005) ha sostenido que es un instrumento de política agraria, entre ellos, para la organización de unidades productivas.

Por eso, las autoridades gubernativas propugnaron el uso de la indicación de procedencia a partir de estudios científicos que habían individualizado productos agrícolas que reunían las condiciones para ser reconocidos como DO o IG, tales como el cordero patagónico y la frutilla de Coronda².

Las Resoluciones 45 (1993) de la SAGyP y 1.367 (1993) del Servicio Nacional de Sanidad y Calidad Agroalimentaria (Senasa) implementaron la IP

2 Denominación de origen frutilla de Coronda(1997) en: Boletín hortícola,17, INTA-Buenos Aires. 
Carne Ovina Patagónica, antes de la firma del Acuerdo de los Adpic por la República Argentina.

Esta IP fue reconocida por esa resolución administrativa como parte de una estrategia de promoción del consumo interno y de las exportaciones. Esta norma tenía como objetivo revertir la pérdida de competitividad del sector (disminución de las existencias del ganado ovino, caída del precio de la lana y decrecimiento del consumo de la carne ovina). Para ello, resaltaba las características del suelo y clima patagónico, libre de contaminación y escasamente modificado por el hombre.

Más allá de los escasos resultados iniciales y la atipicidad de la IP (que no tenía regulación legal en esa fecha); lo cierto es que fue la primera indicación de origen geográfico de productos agrícolas en nuestro país. Además, sirvió de antecedente para el posterior reconocimiento y protección de la IG cordero patagónico.

La idea fue retomada por las autoridades provinciales y remozada a fines de 1999. En esa fecha se iniciaron dos nuevos emprendimientos: uno fue el Programa Santacruceño de carne ovina. El otro fue un proyecto de productores chubutenses.

Poco después, los productores reencauzaron esos programas de fomento hacia el régimen de la Ley 25.380 (sancionada en el año 2000 y reglamentada en el 2009), para solicitar su reconocimiento y protección como IG.

\section{Las indicaciones de origen geográfico protegidas en el marco de la legislación local}

Las provincias fueron pioneras en la regulación de las indicaciones de origen geográfico.

La Legislatura de Chubut sancionó la Ley IX-42 (1998) (antes Ley 4.459, modificada por Ley 5.534). En el marco de esa ley chubutense se reconoció y protegió la DO "Lana Camarones". El derecho de uso fue conferido por el gobierno provincial a la Asociación Civil Lana Camarones, conformada por establecimientos ganaderos, mediante Resolución 108 (2005) del Ministerio de la Producción de esa provincia. 
Otro antecedente provincial fue la Ley 3.296 (1999) de Río Negro sobre DO.

Estas leyes son anteriores al año 2000. En este año, se sancionó la Ley nacional 25.380 (2000) sobre indicaciones de origen geográfico.

Es importante resaltar, que las legislaturas provinciales han continuado sancionando leyes sobre DO o IG, con posterioridad a la sanción de esa Ley nacional. Algunas de estas normas se insertan en programas de promoción de productos de calidad y bajo impacto ambiental.

Entre estas leyes, la Ley 5.224 (2002) de Jujuy estableció un "Régimen de Denominación de Origen”.

Por su parte, la Ley 2.635 (2002) de la Provincia de Santa Cruz instituyó un sistema de DO e IG (con una denotación que difiere de la ley nacional y se aproxima a la definición de IP de la Resolución 8/1995 Mercosur), declarando al Estado provincial titular de las designaciones de origen. Esta norma creó un registro provincial, al establecer la exigencia de la conformación de un órgano de gestión (Consejo de DO y Consejo de IP) entre las condiciones para protección y registro.

Asimismo, la Ley VIII-51 (antes 4.298) (2006) de Misiones aprobó un sistema de IG y DO para productos agrícolas, alimentarios, madera, artesanías, lanas, plantas.

También, la Ley 13.717 (2007) de la Provincia de Buenos Aires estableció un régimen de protección de las IG y DO con alcance local y creó un registro provincial.

En la Provincia de Mendoza se sancionó la Ley 7.809 (2007) que estableció y delimitó la DO Mendoza para el aceite de oliva virgen.

Las normas provinciales prevén que las personas físicas o jurídicas que acceden al sistema gozan de diferentes beneficios, como la promoción de los productos con DO, IG o IP por medio del apoyo publicitario estatal como la Ley 7.809 (2007, art.23 inc. a) de Mendoza, la Ley 5.224 (2002, art.6 inc.e) de Jujuy, la Ley 3.296 (1999, art.6) de Río Negro. También, prevén la certificación oficial de sus atributos por el gobierno de la provincia, la asistencia financiera y la tramitación de la inscripción de la DO en el registro nacional de la propiedad intelectual y en el exterior. 
Estas leyes han regulado las indicaciones de origen geográfico con un contenido más flexible y con mayor alcance que la legislación nacional. Algunas tienen el mérito de haber llenado un vacío normativo frente a la dilación del Congreso Nacional para aprobar la Ley 25.380 (2000) y la demora del PEN en su reglamentación.

Sin embargo, algunas normas locales no se sujetan al régimen nacional en cuanto a los objetos aplicables (extendiéndolo incluso a las artesanías y los servicios). En cuanto a las categorías, algunas incluyen solamente la DO; otras la DO e IG; finalmente otras la DO e IP. Algunas crean un registro provincial como la Ley 2.635 (2002) de Santa Cruz; la Ley 13.71 (2007) de Provincia Buenos Aires y la Ley IX-42 (1998) de Chubut.

También, han adoptado diversas formas de reconocimiento y protección como la DO maní de Córdoba o la DO Mendoza para el aceite de oliva virgen, declaradas mediante ley sin el trámite administrativo preliminar de acreditación de los presupuestos legales.

Es cierto que a mediados del año 2019 la Asociación Olivícola Mendocina (Asolmen) ha presentado la solicitud para su reconocimiento y registro ante la SAGyP de la Nación, luego de un trabajo conjunto con el Ministerio de Economía, Infraestructura y Energía, la fundación IDR, encargada de la trazabilidad y otorgamiento de sello, el INTA, el INTI y el panel de cata de la UNCuyo, especialistas en análisis sensoriales. Sin embargo, hasta la fecha no ha sido reconocida por la autoridad administrativa nacional.

Incluso, las leyes de Santa Cruz, Chubut y Misiones asignan la titularidad pública al Estado provincial, quien confiere el derecho de uso al Consejo de DO.

Estas normas provinciales plantean un interrogante sobre su constitucionalidad. Para responderlo, debemos tener en cuenta el deslinde de competencia Nación-provincias en función del contenido (competencia desleal, propiedad intelectual, patrimonio cultural,etc).

\section{El deslinde constitucional de competencias Nación-provincias}

El art.75 inc.12 de la Constitución Nacional (1853, modificada en 1994) ha asignado al Congreso Nacional la atribución exclusiva de dictar leyes de fondo. Como contrapartida, es una atribución prohibida a las provincias (Const., 
1853, modificada en 1994, art.126). En consecuencia, el Congreso Nacional es el órgano competente para regular la situación jurídica de las cosas (su titularidad), los objetos de propiedad intelectual y establecer los presupuestos para su reconocimiento y protección, plazo de vigencia, competencia desleal, etc. De modo coherente, prohíbe a las provincias ejercer esa atribución. Aclaramos que, excepcional y transitoriamente, las provincias podían legislar en cuestiones de derecho de fondo no reguladas hasta que el Congreso de la Nación dictara una ley nacional sobre la materia.

La Constitución Nacional (1853, modificada en 1994, art.75 inc.12) no se refiere expresamente al derecho agrario. Sin embargo, la doctrina calificada entiende que el Congreso Nacional es competente en materia agraria en forma exclusiva, porque queda comprendido dentro de la noción "legislación de fondo" y en la atribución de "reglar el comercio interprovincial e internacional" (Const. 1853, modificada en 1994, art.75 inc.13) (Pastorino, 2009; Brebbia, 1997), salvo algunas materias sobre las que expresamente confiere facultades concurrentes.

El fomento de la economía es una atribución concurrente Nación-provincias.

El art.75 inc.19 de la Constitución Nacional (1853, modificada en 1994) prevé como atribución del Congreso: "Proveer lo conducente al desarrollo humano, al progreso económico [...] Proveer al crecimiento armónico de la Nación ...” Por su parte, el art.125 (1853 modificada en 1994) autoriza a las provincias a promover su desarrollo económico.

No podemos dejar de mencionar el deslinde de competencia constitucional en relación con el patrimonio cultural y natural, teniendo en cuenta aquellas declaratorias de bienes inmateriales de conocimientos y prácticas culturales (mate y cultivo de la yerba) también protegida como IG (IG yerba mate).

El art.41 (Const. 1853, modificada en 1994) segundo y tercer párrafo, impuso el deber al Estado de establecer normas de preservación del patrimonio cultural, correspondiendo a la Nación la atribución de dictar las normas de presupuestos mínimos, y a las provincias, las necesarias para complementarlas. 


\section{La constitucionalidad de las leyes provinciales de indicaciones de origen geográfico}

Las provincias no pueden legislar sobre objetos de propiedad intelectual, derecho industrial (v.gr. competencia desleal) ni derecho agrario (con el alcance mencionado en los párrafos precedentes) desde la sanción de la Ley 25.380 (2000), pues forma parte del derecho de fondo. Las normas locales, tampoco pueden calificar a las IG ni DO como objeto del dominio público.

En cambio, las provincias puedan dictar normas de fomento con fundamento en la cláusula del progreso (Const., 1853, modificada 1994, art. 125).

Por ello, entendemos que son constitucionales aquellas leyes locales que se limitan a declarar de interés local el sistema jurídico de las indicaciones de origen geográfico, a implementar programas de agregado de valor al producto $\mathrm{y}$ otras medidas de fomento.

No obstante, plantean un debate en torno a la eficiencia y eficacia de su estructura administrativa compleja. En efecto, estas leyes provinciales asignan competencia a diversos órganos locales generando una superposición de funciones de organismos nacionales y provinciales. Por ello deben establecerse mecanismos de articulación y coordinación de las acciones de los distintos niveles de gobierno, con el objeto de sumar esfuerzos y no generar un desgaste de recursos humanos y económicos.

En cambio, son inconstitucionales por invadir competencia de la Nación, aquellas que crean un sistema de indicaciones de origen geográfico con menores requisitos que la legislación nacional o que declaran a estas como bienes de titularidad del Estado provincial y como parte del dominio público.

Además, estas leyes locales plantean interrogantes acerca de su utilidad. En efecto, uno de los objetivos de estas normas locales es facilitar el acceso y el desarrollo de nuevos mercados nacionales e internacionales. Entonces, ¿qué utilidad tiene un signo distintivo que solamente tenga validez en el ámbito local? 


\section{Segunda parte}

\section{La regulación de la indicación geográfica y la denominación de origen en la Ley nacional 25.380}

La Ley 25.380 (2000), sancionada por el Congreso Nacional en cumplimiento del Acuerdo sobre los Adpic (Trips), ha establecido un sistema jurídico para la protección de los nombres geográficos, con el objeto de adaptar la legislación nacional a tratados internacionales y a exigencias de los mercados internacionales (Schiavone y Champredonde, 2012).

Esta ley reglamentó dos categorías de indicaciones de origen geográfico (IG y DO $)^{3}$ para los productos agrícolas. La IG como "nombre geográfico que identifica un producto como originario de una región, localidad, zona cuya calidad se atribuye fundamentalmente a su origen geográfico" (Ley 25.380, 2000, art.2 inc. a). La DO es un "nombre geográfico que identifica un producto originario de una región, localidad, o zona dentro de un área de producción cuyas características particulares y calidad se atribuyen fundamentalmente al medio geográfico, comprendiendo los factores naturales como humanos” (Ley 25.380, 2000, art.2 inc.b).

El marco jurídico de las indicaciones de origen está integrado por la citada Ley, su Decreto reglamentario 556 (2009), resoluciones dictadas por la SAGyP de la Nación, además del CAA, Ley 22.802(1983), Ley 22.362 (1980). Este marco normativo presenta las siguientes características:

Primero, en la República Argentina este régimen jurídico se aplica exclusivamente a productos agrícolas, excluidos los vinos y bebidas espirituosas de origen vínico que se rigen por una ley especial. Ambos regímenes presentan diferencias sustanciales en cuanto a las categorías jurídicas admitidas, antecedentes, fundamento y finalidades.

En efecto, la legislación de vinos prevé la IP, IGy DO, mientras que la Ley 25.380 (2000) prevé solamente la IG y DO. Las primeras DO argentinas reconocidas y registradas fueron de vinos, y el régimen jurídico fue aprobado luego de un reclamo de dos décadas de distintos ámbitos (viñateros y bodegueros,

3 El texto originario de la Ley 25.380 (2000) previó la IP (como centro de producción o fabricación renombrado de un producto) y DO. La Ley 25.966 (2004) suprimió la IP e incorporó la IG. 
científicos y académicos, etc); mientras que el sistema jurídico aplicable a los demás productos agrícolas fue implementado a partir de medidas de fomento de la autoridad gubernamental. La legislación de indicaciones geográficas de vinos tuvo entre otros objetivos, la conversión de las vides hacia productos de variedades calificadas como finas; mientras que la legislación agroalimentaria ha buscado la valorización del producto a partir del origen geográfico como herramienta para el desarrollo rural sustentable y especialmente, de las economías regionales.

Segundo, este sistema jurídico es complejo y disperso en normas nacionales y provinciales de diverso contenido (normas sobre sellos de calidad específica, leyes de fomento, titularidad, protección del patrimonio cultural, etc.). Esta complejidad es consecuencia del deslinde constitucional de competencia Nación-provincia.

Tercero, en la República Argentina (Estado Federal), el control alimentario es descentralizado en lo político y administrativo. En el contexto nacional, la fiscalización de la sanidad y seguridad alimentaria (inocuidad) está a cargo del Sistema Nacional de Control de Alimentos que integra el Servicio Nacional de Sanidad y Calidad Agroalimentaria (Senasa), dependiente del Ministerio de Agricultura, Ganadería y Pesca. En lo local, cada provincia aplica el CAA en su ámbito territorial.

Por su parte, la autoridad de aplicación de la Ley 25.380 (2000) y su modificatoria Ley 25.966 (2004) es la SAGyP. El registro de las IG y DO funciona en el ámbito del Ministerio de Agricultura (Resolución 587, 2010).

En cambio, el Instituto Nacional de Propiedad Industrial (INPI) es la autoridad competente en el procedimiento de registro de marcas y la Secretaría de Comercio aplica la Ley 22.802(1983). Este panorama es más complejo con respecto a las IG declaradas patrimonio cultural inmaterial (IG yerba mate) (Molina, 2018), toda vez que coexisten órganos nacionales, provinciales y municipales competentes para el patrimonio cultural.

Cuarto, el sistema de las indicaciones de origen geográfico está sujeto a un régimen esencialmente de derecho público.

Las IG y DO trascienden el ámbito privado de cada usuario. Cualquier uso indebido o fraudulento puede producir consecuencias perjudiciales no sólo a los productores adheridos al sistema (v.gr.desprestigio del signo) sino 
que puede afectar la economía local, especialmente aquellas regiones cuya estructura económica depende de un producto agrícola.

Quinto, es un régimen jurídico que tiene por finalidad la valorización y diferenciación de productos locales, que facilita la inserción de productos en mercados nacionales e internacionales. En este sentido, es un sello de calidad específica vinculada al territorio.

Sexto, el sistema de indicaciones de origen geográfico presenta peculiaridades en torno a los factores humanos que inciden en la tipicidad del producto, toda vez que es un país de inmigración donde hubo procesos de fusión cultural.

Séptimo, en razón de los beneficios y ventajas del sistema de indicaciones de origen geográfico, las autoridades gubernamentales han fomentado su uso a través de medios jurídicos y económicos, articulándola con programas de valorización de productos.

Octavo, constituyen un signo distintivo de productos con distintos niveles de protección jurídica (Schiavone, 2006). Las vaguedades y lagunas jurídicas en la legislación argentina han generado un debate en cuanto a su naturaleza jurídica.

Aclaramos que en los párrafos siguientes analizaremos cada uno de estos aspectos, excepto el octavo que excede los objetivos del presente artículo.

\section{El sistema jurídico argentino de las indicaciones de origen geográfico aplicable exclusivamente a los productos agrícolas}

En algunos países, el uso de la DO e IG originariamente aplicado a bebidas alcohólicas, se extendió a otros productos agrícolas, incluso a productos industriales y artesanales -como la DO cerámica negra de La Chamba y la DO cerámica de la Ráquira (ambas de Colombia), la DO alfarería de Pomaire (Chile), DO cerámicas de Guaitil y San Vicente (Costa Rica), etc - y a servicios -como en la legislación brasilera (Molina, 2015)-. En Argentina está limitado a productos agroalimentarios. 
Sin embargo, en el derecho público provincial hay algunas leyes provinciales que admiten el registro de productos manufacturados, artesanías como la Ley VIII-51 (2006) de Misiones y Ley IV-42 (1998) de Chubut.

Incluso, algunas incluyen a los servicios como la ley chubutense. Esta ley aprobó un sistema de protección mediante las IG y DO que se aplica a toda clase de productos, incluso servicios. En el marco de esta ley se reconoció la DO “Lana Camarones" en el año 2005.

Esas normas provinciales que autoriza su aplicación incluso a servicios, siguen la tendencia de la legislación latinoamericana. Sin embargo, generan dudas en torno a su constitucionalidad, tema que fue analizado en los párrafos precedentes.

Otro aspecto, es que la Decisión 8 (1995) CMC-Mercosur extiende este sistema jurídico a los servicios. Uno de los países miembros -Argentina- no se ajusta a esa norma.

\section{Sistema de las indicaciones de origen geográfico como régimen esencialmente de derecho público}

Las IGs y DOs de productos agrícolas están sujetas a un régimen de derecho público en su reconocimiento, registro y protección. La autoridad administrativa ejerce una fiscalización permanente del sistema y se encarga de su promoción.

Este órgano estatal ejerce un control administrativo ordinario y extraordinario sobre los Consejos de DO. En efecto, la Ley 25.380 (2000, art.15) ha previsto un recurso de alzada ante la autoridad de aplicación en contra de las decisiones definitivas de la autoridad máxima del Consejo. Asimismo, es organismo de alzada para resolver conflictos entre distintos Consejos.

A los fines de cumplir con la función administrativa de control y promoción (además, dela función registral), la autoridad administrativa goza de prerrogativas públicas exorbitantes, como la potestad reglamentaria y sancionatoria.

Debe tenerse en cuenta que los usuarios de una DO están sujetos a normas de distinta naturaleza. Uno estatutario, regido por el Derecho Civil cuya 
aplicación está a cargo del Consejo de DO (organizado como asociación civil abierta) aunque bajo la supervisión de la SAGyP. Otro administrativo, regido por el CAA, la Ley 25.380 (2000) y el Decreto Nacional 556 (2009), cuya autoridad de aplicación es la SAGyP.

La SAGyP ejerce la potestad sancionatoria sobre los Consejos de DO, los usuarios de las indicaciones de origen geográfico y los demás productores que las usan desleal o fraudulentamente sin que se les haya conferido el derecho de uso previa acreditación de los requisitos legales y estatutarios.

Las infracciones y contravenciones cometidas por los usuarios de este sistema jurídico, pueden ser sancionadas con: multa de hasta cincuenta (50) veces el valor de mercado que tuviera el producto en infracción pudiendo duplicarse en caso de reincidencia, suspensión temporal del uso de la IG o DO de que se trate, cancelación definitiva del uso de la IG o de la DO. Entre sus atribuciones, puede ordenar el decomiso sin intervención judicial.

La SAGyP puede incluso imponer las mismas sanciones a personas físicas o jurídicas que no estuvieran adscritas al sistema de protección cuando constatare: el uso indebido de una IG o DO; la utilización de nombres comerciales, signos o emblemas que por su similitud gráfica o fonética puedan inducir a error sobre la naturaleza o el origen de los productos agrícolas; también, por el empleo indebido de nombres geográficos protegidos en etiquetas o marbetes, documentación comercial o publicidad de productos, aunque vayan precedidos por los términos "género", "tipo”, "estilo”.

El ejercicio de esta potestad sancionatoria aun frente a personas no adheridas al sistema jurídico y que tiene lugar en sede administrativa, es uno de los aspectos en que las indicaciones de origen geográfico se diferencian de la protección de los demás objetos de propiedad intelectual.

\section{La legislación agrícola y las indicaciones de origen geográfico}

El sistema jurídico de las indicaciones de origen geográfico ha sido concebido para la valorización del producto agroalimentario a partir de su tipicidad. Particularmente, en el ámbito nacional se han implementado programas de calidad de los productos y agregado de valor priorizando, entre otros, los productos con DO o IG. 
Este régimen jurídico forma parte de la legislación agraria, en tanto regula la calidad genérica y específica de los productos.

La Organización Internacional de Normalización (ISO) define calidad en función de la medida en que el conjunto de propiedades del producto satisface al consumidor. Es una noción subjetiva que además está sujeta a cambios con el paso del tiempo. Sobre los productos alimenticios hay que distinguir: 1) Componentes nutritivos o dietarios (suficiencia alimentaria). 2) Calidad higiénica, es decir, los requisitos básicos que deben cumplirse en función de las normas vigentes, para que los alimentos sean inocuos, no estén contaminados o adulterados (seguridad alimentaria). 3) Las valoraciones subjetivas (ambientales, sociales, culturales) que están representadas, entre otros, en los productos con DO (Pastorino, 2005). Otros autores unifican los dos primeros, al definir la calidad genérica como equivalente a inocuidad; es decir, sólo distinguen la calidad genérica y la específica (esta última, referida a los atributos de valor) (Schiavone, 2006).

En la República Argentina, los estándares generales de producto (inocuidad) están fijados en el CAA (1969). La comercialización exige la conformidad con las normas de identificación de mercaderías previstas en la Ley 22.802 (1983) de Lealtad Comercial.

Por su parte, la calidad específica — facultativa y voluntaria - se refiere a la valoración de sus características particulares y a las diferencias de los productos, de acuerdo con determinados parámetros: su calidad nutricional u otro valor (productos orgánicos, productos vinculados al origen geográfico, etc.) (Schiavone y Champredonde, 2008).

En este sentido, las indicaciones de origen geográfico son signos distintivos de una calidad específica vinculada al territorio, para resaltar aquellas características que los hacen diferentes: su tipicidad.

\section{El concepto de tipicidad de los productos agrícolas dentro de un marco jurídico constitucional abierto a la inmigración}

La tipicidad ha sido definida por la presencia de una calidad específica en el producto, cuando ésta resulta de la incidencia de prácticas y saberes culturales propios de la región y tienen la propiedad de ser distinguido de 
productos similares (Schiavone et al., 2008). Esta calidad específica resulta de la confluencia de factores territoriales y humanos.

En el derecho comparado, los diversos sistemas jurídicos han recogido distintas definiciones de tipicidad, para establecer presupuestos para el reconocimiento de una IG y DO. Algunos hacen hincapié en la reputación, otros en su valor económico o su valor cultural, en sus tradiciones, otros en sus factores naturales.

El Comité permanente de la OMPI en sus documentos ha aclarado que la tipicidad (o especificidad) se basa "en el carácter distintivo del producto, es decir, su capacidad para distinguirse de los demás productos” (Documento SCT 10/4, 2003, pto.20 y 24).

Lo cierto es que la tipicidad del producto remite al grupo humano donde se originan las prácticas que influyen en esa calidad específica, particularmente en los productos procesados o transformados.

¿Qué características presenta la noción de tipicidad en la República Argentina como sociedad multicultural y cosmopolita?

Nuestro país fue una colonia española hasta la declaración de independencia de 1816, es decir, nuestra sociedad tiene una larga tradición hispana. Por otro lado, la República Argentina desde su conformación como Estado no sólo estuvo abierta a la inmigración sino que el art.25 de la Constitución Nacional (1853, modificada en 1994) impuso al Estado nacional el fomento de la inmigración, especialmente, europea. Como corolario, el art.20 de la Constitución Nacional (1853, modificada en 1994) reconoció la igualdad de derechos civiles de nacionales y extranjeros.

Esta característica cultural e histórica de la sociedad argentina estimulada por el constituyente de 1853, tiene relevancia para el régimen de las indicaciones de origen geográfico en dos aspectos: primero, en cuanto a la identificación y delimitación de la tipicidad de un producto. Segundo, en cuanto a la confusión terminológica particularmente en la legislación y jurisprudencia ${ }^{4}$ argentina de principio y mediados del siglo XX, al pasar al uso común las denominaciones de origen europeas para designar un tipo de producto (Molina, 2015; Cabaleiro, 2012).

$4 \quad$ Sociedad Pommery y Greno, y otros con Gutiérrez y de la Fuente Ltada, Corte Suprema de Justicia de la Nación. (1960). Fallos $T^{\circ} 248$, p.385. 
¿Cómo identificar y delimitar un producto típico en una sociedad multicultural?

La tipicidad es más difícil de definir en comunidades multiculturales abiertas a la inmigración (Champredonde, 2012). Las modificaciones internas en el seno del grupo humano, su mestizaje, su fusión cultural o inculturación son determinantes de la calidad específica (Champredonde et al., 2016).

El aspecto humano que define la tipicidad del producto requiere estudios antropológicos e históricos. Estos deben analizar ese proceso de inculturación. Recién empiezan a aflorar las investigaciones sobre aspectos históricos y antropológicos.

En la República Argentina, la Ley nacional 25.380 (2000) exige la acreditación de tipicidad y la reputación del área de producción para el reconocimiento de una IG y DO.

Los productos amparables con indicación de origen geográfico deben acreditar los factores naturales y humanos que determinan la especificidad del producto, es decir, deben probar los caracteres cualitativos particulares que lo distinguen de otros producidos en condiciones ecológicas similares. La acreditación de los factores históricos y culturales se apoyan en investigaciones científicas. Los factores naturales, se verifican con análisis y con la intervención de un panel de degustadores, quienes evalúan si un producto es típico.

\section{Los sellos de calidad en la República Argentina: ¿marcas o indicaciones de origen geográfico?}

En la República Argentina se han aprobado diversos instrumentos de identificación y valorización de productos, como las indicaciones de origen geográfico, las marcas nacionales y provinciales. Estas últimas tienen un alcance más amplio, toda vez que puede aplicarse a todos los productos con calidad específica, no sólo los vinculados al origen geográfico sino también, a los productos orgánicos, tradicionales, etc.

En los últimos diez años, se han sancionado numerosas normas provinciales, entre ellas: 
La Ley 2.189 (2005) de La Pampa, aprobó el sello de calidad "Producto de la Pampa” y la Ley 7.163 (2001) de Salta aprobó el "Sello de Producto Salteño" aplicable, entre otros, a productos con IG y DO.

En lo nacional, mediante la Ley 26.967 (2014) se creó el signo "Alimentos Argentinos, una elección natural" (Argentine Food a Natural Choice) y se registró a nombre de la SAGyP en varias clases del Nomenclador. Este signo registrado funciona como una marca país, cuyo uso es autorizado a las empresas que adaptan su producción a protocolos de calidad específicos y su observancia es auditada.

Estos programas nacionales y provinciales de valorización del producto (Schiavone et al., 2008), aplicable a productos tradicionales y orgánicos, también, se han articulado con el régimen de indicaciones de origen geográfico. Los productos con DO o IG que usan estos sellos de calidad específicos, pueden acceder a ciertos beneficios (exenciones impositivas, asistencia financiera, publicidad oficial, capacitación, etc. $)^{5}$.

\section{Las indicaciones de origen geográfico como herramienta de fomento de las economías regionales}

En nuestro país, numerosos estudios científicos habían individualizado productos agrícolas que tenían cualidades para ser reconocidos como DO o IG. Sin embargo, había ciertos obstáculos y condicionamientos que impedían su difusión en el mercado interno como la falta de integración de los productores, desconocimiento de este régimen jurídico.

Por esto, el Gobierno nacional y los gobiernos provinciales aprobaron normas legales e instrumentaron medidas de diversa índole tendientes a promover la organización e integración de los productores y su capacitación, articulando medios económicos y jurídicos (Molina, 2016). Entre ellos, el Decreto 1.341 (2006) prevé que los productos que cuentan con una DO o una IG tienen un reintegro a la exportación adicional del 0.5 \%, además, de publicidad oficial, asistencia técnica, financiamiento.

Los procesos de valorización del producto han sido impulsados desde los gobiernos locales y nacional, con la participación de los productores con

$\overline{5}$ Ver datos:http://www.alimentosargentinos.gob.ar/HomeAlimentos/HAV/ 
distinto grado de involucramiento (Schiavone et al., 2008). Algunos casos poseían experiencias de trabajo conjunto previo a la solicitud de reconocimiento y registro de la $\mathrm{IG} / \mathrm{DO}$ como la frutilla de Coronda -Santa $\mathrm{Fe}^{6}$ y el salame de Colonia Caroya (Champredonde et al., 2016), cordero patagónico. Tales antecedentes se enmarcan en acciones de investigación y extensión de las Universidades y del INTA.

Recordemos que el fomento es toda acción dirigida a proteger o promover. Es una función de naturaleza pública, de estímulo de ciertas actividades económicas o áreas de producción con distintas finalidades (Dromi, 2009; Molina, 2016) como el desarrollo productivo, inserción en mercados externos, aumento de la productividad, etc.

Tomando estos medios económicos y jurídicos como variables de estudio en un ámbito temporal (últimos diez años) y espacial (todo el territorio nacional), podemos observar un proceso muy lento con superposición de acciones gubernamentales en los contextos nacional y provincial. Puede observarse entonces que el reconocimiento y registro de DO e IG de productos agrícolas en la República Argentina estuvo precedida de programas estatales en pos de esos objetivos.

Ahora bien, el registro de una IG y DO no dinamiza el desarrollo rural ni aumenta el precio del producto de forma automática, ni las prácticas culturales son valoradas inmediatamente en el mercado. Ello depende del modo como se lleve a cabo el proceso de identificación, organización y valorización (Bramley, 2011; Vandecandelaere, 2011).

Especialmente, son indispensables las estrategias de comercialización, publicidad y la educación del consumidor. La actividad estatal de fomento debe encaminarse a partir del registro de una DO e IG, a la capacitación en gestión comercial y publicidad.

6 En el año 1994 se formó una asociación civil que comenzó a actuar como órgano de gestión. "Desde 1996 hasta 1998 los productores presentaron en el mercado interno cajitas de 1/4 kg de frutillas con un logo de DO, con etiquetas numeradas y cintas adhesivas inviolables", Diario La Nación (/2000, 15 de julio). 


\section{Tercera parte}

\section{Las DO e IG argentinas protegidas y registradas en el marco de la Ley 25.380: una mirada retrospectiva}

Hasta el año 2018 se habían reconocido y registrado sólo cinco IG (IG salame típico de Colonia Caroya mediante la Resolución 37 (2014) SAGyP, la IG cordero patagónico mediante Resolución 326 (2014) SAGyP, la IG melón de Media Agua mediante la Resolución 549 (2014) SAGyP, la IG Yerba Mate argentina por Resolución 13 (2016), la IG Alcauciles platenses por Resolución 31 (2016).

Por su parte, se habían reconocido tres DO: la DO chivito criollo del norte neuquino por Resolución 950 (2010) SAGyP, la DO Salame de Tandil mediante Resolución 986 (2011) del Ministerio de Agricultura, DO membrillo rubio de San Juan por Resolución 14 (2018).

Hay que agregar la DO "Lana Camarones" fue otorgada mediante la Resolución 108 (2005) (2005) del Ministerio de la Producción de Chubut a productores organizados en la Asociación Civil Lana Camarones.

También, la DO Mendoza de aceite de oliva virgen reconocida por la Ley 7.809 (2007) y la DO Maní de Córdoba, reconocida mediante la Ley 10.094 (2012), ambas protegidas en el ámbito provincial; pero sin observar las normas nacionales y sin haber sido inscrita en el Registro Nacional.

Hay numerosos proyectos de DO o IG como el aceite de oliva Cruz del Eje, cordero argentino-Región Centro, frutilla de Coronda, manzanas de San Francisco del Chañar, duraznos de San Pedro, etc., que no han sido reconocidos y registrados por la SAGyP por distintos motivos, pero ponen de manifiesto la acción del Gobierno hacia esos objetivos.

Una situación peculiar se ha presentado en torno a los proyectos de DO Pampa para carne vacuna que presenta distintas aristas sobre su delimitación territorial y las razas vacunas a certificar. Estos proyectos han despertado interés en los ganaderos sin mayor impulso estatal pero también muestran una tensión por acaparar la designación "Pampa” para la emblemática carne vacuna argentina. 
El análisis del régimen jurídico y actividad desarrollada por las autoridades nacionales y provinciales nos lleva a algunas reflexiones.

Primero, el proceso para incorporar esta figura jurídica foránea a la estructura económica argentina y su mercado interno ha sido muy lento y ha estado precedido de políticas públicas activas de fomento de su uso, capacitación.

Segundo, la proliferación de normas provinciales que asignan competencia a distintos órganos nacionales y provinciales con superposición de funciones, tornan complejo el régimen de indicaciones de origen geográfico. Muchas acciones gubernamentales no se encuentran coordinadas, lo que genera desgaste de recursos humanos y económicos.

A título ilustrativo mencionamos una situación fáctica que se presenta en la Provincia de Mendoza y se reitera de modo similar en otras provincias.

La Ley 7.809 (2007) estableció la DO Mendoza (DOM) para el Aceite de Oliva Virgen, delimitando como zona de origen todo el territorio provincial y mencionando como objetivos: valorizar la producción olivícola, garantizar la procedencia geográfica y calidad del producto, favorecer la integración vertical y horizontal de los productores, promover el envasado en origen, mejorar las posibilidades de comercialización, etc.

Esta norma -de modo similar a la Ley 10.094 (2012) de Córdoba-, protege la DO sin sujetarse a la Ley nacional y sin un procedimiento previo de acreditación de la tipicidad, esto es, de la consiguiente influencia de los factores humanos y ambientales en las características del producto.

Además, esta norma provincial asignó funciones al Ministerio de Economía y creó un Consejo Provincial de Orígenes con competencia para fiscalizar y promover el sistema; mientras que en el ámbito nacional la SAGyP es autoridad de aplicación de la Ley 25.380 (2000). Además, el INPI es la autoridad de aplicación de la Ley 22.362 (1980) y la Secretaría de Comercio aplica la Ley 22.802(1983).

Este marco normativo tan profuso y la consiguiente asignación de competencia a diversos órganos es una clara demostración de la falta de coordinación entre los distintos niveles de gobierno y de la confusión en torno a la naturaleza jurídica de las indicaciones de origen geográfico. que va en 
desmedro de la difusión de este régimen jurídico entre los productores y su conocimiento por el consumidor.

Tercero, hay normas locales que no se sujetan a la legislación nacional ni respetan estrictamente el deslinde de competencia establecido en la Constitución Nacional. Esto genera dudas sobre su constitucionalidad en relación con los objetos comprendidos, a las formas de reconocimiento, a la asignación de la titularidad pública al Estado provincial.

Cuarto, no están registradas todas las DO argentinas (DO maní de Córdoba, DO Mendoza de aceite de oliva virgen y DO lana camarones), lo que dificulta el conocimiento y oponibilidad de las indicaciones de origen geográfico en el ámbito nacional.

Quinto, un aspecto que también pone de manifiesto la confusión acerca de la naturaleza jurídica de las indicaciones de origen geográfico, es que algunas leyes provinciales adhieren a las disposiciones de la Ley Nacional 25.380 (2000); entre ellas, la Ley 7.809 (2007) de Mendoza. Entonces, si las indicaciones de origen geográfico son objetos de propiedad intelectual (materia de fondo), la ley local no tiene que adherir a una ley dictada por el Congreso Nacional en virtud de sus atribuciones exclusivas, sino que debe ajustarse a ella conforme al principio de supremacía consagrado en el art.31 de la CN (Const.1853).

Sexto, la ley nacional ha omitido mencionar aspectos relevantes para dilucidar su naturaleza jurídica, entre ellos: su condición jurídica y la titularidad de la DO e IG, vías judiciales para la defensa frente al uso indebido o desleal.

Séptimo, la legislación nacional no exige la conformación de un órgano de gestión para la IG. Esta omisión obstaculiza su calificación como sello de calidad específica. En efecto, para garantizar al consumidor que un producto alimenticio tiene efectivamente los atributos de valor, debe existir una entidad independiente (organismo certificador) que verifique que el producto y expida el sello de calidad (Oyarzún y Tartanac, 2002).

Es cierto que, en la práctica, la SAGyP ha velado por la conformación del órgano de gestión. En este sentido, la Resolución 326 (2014) estableció en su art.3 que: "La expedición de los Certificados de Derecho de Uso de la IG Cordero Patagónico serán emitidos [...] una vez conformados los respectivos Consejos Reguladores..." 
Sin embargo, esas medidas administrativas no modifican los defectos de la norma legal ni atenúan las dudas en torno a su naturaleza jurídica.

En efecto, en la causa judicial "Establecimiento Canale"7, la Cámara Federal ha interpretado (aunque referido a la DO) que constituye un indicador del origen geográfico de ciertos productos que responden a condiciones particulares de producción.

Octavo, las normas nacionales no se adecúan a las normas emitidas por los órganos del Mercosur, en cuanto a la definición, categorías, objetos a los cuales se aplica, etc.

\section{Conclusiones}

La Ley 25.380 (2000), sancionada por el Congreso Nacional en cumplimiento del Acuerdo sobre los Adpic, estableció un sistema de normas para la protección de los nombres geográficos, regulando dos categorías: IG y DO. El régimen jurídico argentino presenta las siguientes características:

Primero, es un sistema jurídico que se aplica a productos agroalimentarios.

Segundo, la legislación sobre indicaciones de origen geográfico integra el marco jurídico de la agroindustria y está sujeto a un régimen esencialmente de derecho público complejo y además, disperso en razón de la forma federal del Estado Argentino.

Tercero, la DO es un sello de calidad específica (tipicidad) que tiene por objeto la valorización de los productos a partir de su origen.

Cuarto, las indicaciones de origen geográfico han sido usado como estrategia para el desarrollo de las economías regionales, articulándolo con programas de agregado de valor al producto.

Este sistema jurídico complejo y disperso de las indicaciones de origen geográfico no ha sido el marco normativo adecuado para su desarrollo y consolidación.

7 Cámara Federal de General Roca (2014)., Sentencia. Establecimiento Humberto Canale SA con Munetta, Patricio por cese uso de marcas. https://ar.vlex.com/libraries/jurisprudencia-argentina-26. 
Por un lado, adolece de numerosos vacíos, tales como la indeterminación de la titularidad sobre el nombre geográfico, la inexistencia de normas para el registro de DO o IG extranjeras, inexistencia de previsión legal de un órgano de gestión de la IG, etc.

Por otro lado, la proliferación de normas locales que en algunos casos invaden la competencia exclusiva del Congreso Nacional, genera confusión en el comercio, particularmente en el consumidor.

Hay numerosos aspectos normativos que deben reformularse y coordinarse.

Deben introducirse modificaciones a la legislación vigente para superar defectos y vacíos normativos. Particularmente, deben regularse aspectos indispensables para la definición de su naturaleza jurídica superadora de la óptica de mero indicador de origen. La correcta configuración de su naturaleza jurídica introducirá claridad en el régimen jurídico de las indicaciones geográficas y por consiguiente, seguridad jurídica.

Las leyes provinciales deben ser revisadas y depuradas, debiendo derogarse las disposiciones que invadan competencia de la Nación. Las provincias que han reconocido y protegido DO o IG locales (maní de Córdoba, lana camarones, aceite de oliva virgen de Mendoza) deben sujetarse a la Ley nacional e inscribirse en el registro nacional. La Asociación Olivícola Mendocina ha dado un paso en este sentido, presentando la solicitud para su reconocimiento y registro ante la SAGyP de la Nación.

Finalmente, el apoyo estatal no debe circunscribirse únicamente a la primera etapa de organización e integración de productores y capacitación, sino que debe continuar en una segunda etapa. Por un lado, es indispensable profundizary extender la formación sobre la IGy DO: productores, comerciantes, consumidores. Por otro, deberían destinarse recursos a la investigación de nuevos mercados y a la capacitación en estrategias de marketing y publicidad.

No debe perderse de vista que el mayor valor del producto deriva del efectivo conocimiento por el consumidor y de su disposición a pagar más por ese producto con tipicidad. Especialmente, debe asesorarse a los productores sobre las vías legales para la defensa de la indicación de origen geográfico, frente al uso desleal por terceros. 


\section{Referencias bibliográficas}

Boggiano, A. (1995). Fundamento del derecho de la integración en el derecho argentino. Revista de Derecho Comercial y de las Obligaciones ( $\left.T^{\circ} 28-A\right), 281-290$.

Bramley, C. (2011, 22 a 24 de junio). Estudio del impacto socioeconómico de las indicaciones geográficas: consideraciones para el mundo en desarrollo [ponencia]. Departamento de Economía Agrícola, Extensión y Desarrollo Rural, Universidad de Pretoria, Sudáfrica. Simposio Mundial sobre Indicaciones Geográficas, Lima, Perú.

Brebbia, F. (1997). Derecho Agrario. Editorial Astrea.

Carrau, J.G. (2008). Denominaciones geográficas en el derecho de la unión europea y de la organización mundial de comercio. Editor Tirant lo Blanch.

Cabaleiro, H. (2012, 5 de mayo). Denominación de origen: nuestro sello. Actualidad/ Diario La Prensa. http://www.laprensa.com.ar/391977-Denominacion-de-origennuestro-sello.note.aspx

Champredonde, M. (2012). "¿Qué es un producto típico certificable mediante IG/ DO en el contexto Latinoamericano? Ejemplos a partir de casos argentinos", Perspectivas Rurales. Nueva época (Año 10 N¹9), Argentina, pp.61-63.

Champredonde, M.; Carduza, F. y Casablanca, F. (2016). Paneles de evaluación sensorial en la identificación y caracterización de alimentos típicos. Aprendizajes a partir de la construcción de la IG del Salame de Colonia Caroya. Revista Iberoamericana Viticultura, Agroindustria y Ruralidad 3 (8), 24-40.

Dromi, R. (2009). Derecho Administrativo. Ediciones Ciudad Argentina.

Esquivel, E. (2014). Denominaciones de origen: instrumento eficaz para el desarrollo económico productivo regional. 37th Congreso Mundial de la Vid y el Vino, Provincia de Mendoza, Argentina.

Herrmann, R. (2011, 22 a 24 de junio). La economía de la protección de las indicaciones geográficas [ponencia]. Simposio Mundial sobre Indicaciones Geográficas, Lima, Perú.

Molina, M. (2015). La protección de la denominación de origen, indicación geográfica e indicación de procedencia. Estudio comparativo de las legislaciones de los Estados latinoamericanos y español. Revista Iberoamericana de Viticultura, Agroindustria y Ruralidad (RIVAR), 2 (6), 46-69.

Molina, M. (2016). Las designaciones de origen geográfico como medio de fomento del desarrollo rural sustentable en el derecho argentino. Revista de Derecho Administrativo 103 (1), 259-274.

Molina, M. (2017). Conflictos de las marcas y las designaciones de origen geográfico nacionales y extranjeras. Revista chilena de Derecho,44 (1), 107-132.

Molina, M. (2018). Las Denominaciones de Origen protegidas simultáneamente bajo un régimen de propiedad intelectual y de patrimonio cultural intangible: un análisis en el marco del derecho argentino. RIVAR. 5(15), 135-156.

Oyarzún, M y Tartanac, F. (2002). Estudio sobre los principales tipos de sellos de calidad en alimentos a nivel mundial. Estado actual y perspectivas de los sellos de calidad en productos alimenticios de la agroindustria rural en América Latina. http://www.alimentosargentinos.gob.ar/contenido/publicaciones/calidad/BPM/ diferenciacion/sellosdecalidadFAO.pdf ]

Pastorino, L. (2005). La política europea de desarrollo rural sostenible ¿obstáculo o modelo para el Mercosur? . Ediciones al margen. 
Pastorino, L. (2009). Derecho Agrario Argentino. Abeledo Perrot.

Sampedro, M. (2011). Denominaciones de origen. Revista el Derecho, $T^{\circ} 244,477-484$.

Schiavone, E. (2006). Regulación de las indicaciones geográficas y denominación de origen. Revista Diario Judicial $\mathrm{T}^{\circ} 3,141$.

Schiavone E. y Champredonde M. (2008, 27 al 31 de octubre). Estado actual y evoluciones posibles del marco legal argentino concerniente a la valorización de alimentos con Identidad Territorial. Aportes para un proceso de mejoramiento. IV Coloquio Internacional de la Red SIAL: ALFATER, Mar del Plata, Argentina.

Vandecandelaere, E. (2011). "Razonamientos socioeconómicos subyacentes al desarrollo de las indicaciones geográficas: combinar las dimensiones económicas y de bien público para contribuir al desarrollo sostenible de los territorios", Organización de las Naciones Unidas para la Agricultura y la Alimentación (FAO), Simposio Mundial sobre Indicaciones Geográficas, Lima, 22 a 24 de junio de 2011.

\section{Normativa}

\section{Leyes nacionales}

Congreso Nacional República Argentina. (1966, 17 de noviembre). Ley 17.011. BO N²1068. Congreso Nacional República Argentina. (1969, 28 de julio). Ley 18.284. BO N²1732. Congreso Nacional República Argentina. (1980, 18 de diciembre). Ley 22.362. BO N²4568. Congreso Nacional República Argentina. (1983, 11 de mayo). Ley 22.802. BO N²5170. Congreso Nacional República Argentina. (1995, 5 de enero). Ley 24.425. BO N²8054. Congreso Nacional República Argentina.(2000, 12 de enero). Ley 25.380. BO N²9565. Congreso Nacional República Argentina. (2004, 21 de diciembre). Ley 25.966. BO N³0552. Congreso Nacional República Argentina. (2008, 29 de diciembre). Ley 26.433, BO N³1561. Congreso Nacional República Argentina. (2014, 1 de septiembre). Ley 26.967. BO №32958.

\section{Leyes provinciales}

Legislatura Provincia Chubut. (1998, 16 de diciembre). Ley IX-42 (antes N4.459). Legislatura Provincia Río Negro. (1999, 29 de julio). Ley 3.296. BO N³698. Legislatura Provincia Jujuy. (2001, 12 de enero). Ley 5.224. B.O Anexo 5. Legislatura Provincia Salta. (2001, 11 de diciembre). Ley 7.163. B.O №16289. Legislatura Provincia Santa Cruz.(2002, 29 de octubre). Ley 2.635. BO N³510. Legislatura Provincia La Pampa. (2005, 2 de septiembre). Ley 2.189. BO N²647. Legislatura Provincial Río Negro (2005, 29 de septiembre). Ley 3.992. BO N4346. Cámara de Representantes Provincia Misiones. (2006, 12 de julio). Ley VIII-51 (antes 4.298). BO N¹1811.

Legislatura Provincia Buenos Aires. (2007, 29 de agosto). Ley 13.717. BO N²5727. Legislatura Provincia Mendoza. (2007, 11 de diciembre). Ley 7.809. BO N²8049. Legislatura Provincia Córdoba. (2012, 17 de octubre). Ley 10.094. BO XCIX N¹74. 


\section{Resoluciones y reglamentos administrativos}

Secretaría Agricultura, Ganadería y Pesca de la Nación.(1993, 19 de marzo). Resolución 45. BO N²7601.

Servicio Nacional de Sanidad y Calidad Agroalimentaria.(1993, 17 de diciembre). Resolución 1.367. BO N²7788.

Consejo MERCOSUR.(1995, 5 de agosto). Resolución 8. http://gd.mercosur.int/.

Ministerio de la Producción de Chubut.(2005, 3 de junio). Resolución 108. BO Nº758.

Poder Ejecutivo Nacional República Argentina.(2009, 18 de mayo). Decreto 556. BO $\mathrm{N}^{\circ} 31655$.

Secretaría Agricultura, Ganadería y Pesca República Argentina. (2010, 17 de diciembre). Resolución 950. BO N³2050.

Ministerio de Agricultura de la Nación, República Argentina. (2011, 5 de octubre). Resolución 986. BO N³2249.

Secretaría Agricultura, Ganadería y Pesca de la Nación.(2014, 12 de marzo). Resolución 37. $\mathrm{BO} \mathrm{N}^{\circ} 32844$.

Secretaría Agricultura, Ganadería y Pesca de la Nación. (2014, 17 de septiembre). Resolución 326. BO N³2970.

Secretaría Agricultura, Ganadería y Pesca de la Nación. (2014, 9 de diciembre). Resolución 549. BO N³3026.

Secretaría de Agregado de Valor de la Nación.(2016, 15 de marzo). Resolución 13. BO №33337.

Secretaría de Agregado de Valor de la Nación.(2016, 21 de abril). Resolución 31. BO N³3362.

Secretaría de Alimentos de la Nación.(2018, 17 de octubre). Resolución 14. BO №33976.

\section{Jurisprudencia}

Cámara Federal de General Roca, Argentina. Establecimiento Humberto Canale SA con Munetta, Patricio por cese uso de marcas. (2014). https://ar.vlex.com/libraries/ jurisprudencia-argentina-26.

Cámara Nacional de Apelaciones Civil y Comercial, Sala I, Argentinalnstitut National des Appellations d'origine con Resia.(1990). http://jurisprudencia.pjn.gov.ar/ documentos/jurisp/index.jsp

Cámara Nacional de Apelaciones Civil y Comercial, Sala III, Argentina Valentín Bianchi SACl con Instituto National des Appellations d'origine. (1989). http://jurisprudencia. pjn.gov.ar/documentos/jurisp/index.jsp

Corte Suprema de Justicia de la Nación Argentina Sociedad Pommery y Greno, y otros con Gutiérrez y de la Fuente Ltada. (1960). Fallos T²48, p.385. 